\title{
EXCLUSION IN INCLUSION: \\ EXPERIENCES OF LEARNERS WITH ALBINISM IN SELECTED MAINSTREAM AND SPECIAL SCHOOLS IN ZAMBIA
}

\author{
Thomas Mtonga, \\ Esther Lungu, \\ Kalisto Kalimaposo, \\ Joseph Mandyata ${ }^{\mathrm{i}}$ \\ School of Education, \\ Department of Educational Psychology, \\ Sociology and Special Education, \\ University of Zambia, \\ Lusaka, Zambia
}

\begin{abstract}
:
Albinism is an inherited skin pigmentation condition which affects all races in the world. However, the condition is more conspicuous among the black population because of the absence of pigmentation which leads to some whitish appearance. This condition also leads to multiple disabling experiences to the individuals with albinism. The overriding aim of the study was to establish the learning experiences of learners with albinism in both regular and special schools. The study was located within an interpretive qualitative paradigm and used a phenomenology research design. The Interpretive Phenomenological Analysis (IPA) was used to explore in detail how participants made sense of their personal and social world with regard to learners with albinism in regular and special schools. The researchers conducted one-on-one interviews with the participants and content - analyzed the data. Parents of learners with albinism, teachers, school administrators and learners with albinism participated in interviews. The findings revealed that in regular schools' learners with albinism tended to exclude themselves from other learners so as to avoid discrimination and stereotypes surrounding their condition. The findings also confirmed the existence of myths and stereotypes regarding albinism. The findings further revealed that teachers in regular schools were not patient with learners with albinism and did not give them extra attention and that some teachers used negative comments and did not want learners with albinism in their classes. It was observed that the majority of learners with albinism felt more secure in special schools rather than regular schools. Parents of children with albinism supported the idea of learners with albinism learning in special schools where the learning environment was conducive for them. The study recommended inter alia that government through the
\end{abstract}

i Correspondence: email joseph.mandyata@unza.zm 
Ministry of Education should enhance teacher education programmes by providing requisite knowledge and skills to trainee and serving teachers on handling learners with albinism and other disabilities. School administrators, teachers, learners and the community should raise sensitization and awareness campaigns on disability issues.

Keywords: albinism, special schools, regular schools, special needs, disability

\section{Introduction}

Learners with Albinism have some very special needs in the classroom and elsewhere in the school because of their low vision, sensitivity to bright light and tendency to sunburn easily. With understanding of their special needs and knowledge of techniques for handling them, teachers and other members of the school community can help learners with albinism enjoy school and learn normally. However, without the needed understanding and adaptations, the teacher may be puzzled and frustrated and learners with albinism may find school unpleasant. There appears to be a dearth of information in Zambia on how to help learners with albinism in school as very little has been documented. To date, in many African countries and Zambia in particular, we still need to answer the question: what is the best school system for learners with albinism? Many authors have labored to answer this question in their own way. However, the answers do not seem satisfactory, and they do not seem to end the exclusion of learners with albinism. This study sought to unveil the irreconcilable contradictions in which learners with albinism find themselves in the pursuit of their education in the Zambian school system.

The term albinism is derived from the Latin word albus meaning white. Albinism is a genetically inherited, autosomal recessive physical condition where there is a shortage or absence of the melanin pigment which affects the eyes, hair and skin (Nasr, 2010). People living with albinism are particularly vulnerable to skin cancer and a range of eye problems that can lead to blindness. Nevertheless, the complications may be prevented by wearing dark glasses, appropriate clothes and by lifelong usage of an antiactinic skin cream according to Lund and Gaigher (2002). Albinism occurs more frequently amongst black people than amongst other population groups. Albinos tend to have light hair, skin and eyes, their other facial features and hair texture resemble those of Africans and they are usually born into black African families, hence they tend to identify with the black rather than white communities. Owing to their differences in terms of appearances, albinos do not fit into either the black or white groups. For this reason, they tend to be subject to various myths and stereotypes.

Ntinda (2008) states that in some parts of Africa, people with albinism are perceived as 'sacrificial lambs' (something to be sacrificed for the good of others). Albinos in most parts of Africa are wanted for their hands or genitals which are regarded to be the strongest parts of their bodies. Albinos are believed by some to possess supernatural or magical powers. The myths associated with albinism in most parts of Sub-Saharan 
Africa have a profound influence on their lives from the cradle to the grave. The beliefs and superstitions surrounding the condition affect family life and interfere with access to education, employment and marriage. One of the most common misconceptions about albinism is that it is contagious. Like people with leprosy or physical disabilities, people with albinism were traditionally segregated in most parts of Africa. Today this continues as children with albinism are prevented from mixing with other children for fear that their 'disease will spread.' Some people would not shake hands with people with albinism while others refuse to sit next to people with albinism in class, on a bus or in a taxi. Some people would not touch what has been touched by an albino and others would not share a meal or utensils with an albino. In some circles if a person with albinism has touched food, it would not be eaten by anyone else. Similarly, if a person with albinism has drunk from a cup, the cup will be broken as it is regarded as contaminated. Anything touched by an albino is regarded as contaminated, therefore, albinos cannot sell anything as they would not have customers. The notion that albinism is contagious leads to a number of different actions to avoid 'catching' the condition. Spitting is a common response to meeting a person with albinism. In some parts of Africa, spitting on the ground or spitting inside one's shirt is a way of warding off evil spirits associated with albinism when you meet an albino. Pregnant women spit on their stomachs when they meet a person with albinism in the belief that the act would prevent their unborn child from being born with albinism. The immediate consequence of such beliefs is the social exclusion of people with albinism resulting in psychological problems for albinos such as withdrawal from society and inferiority complexes.

In some African communities, learners with albinism are not encouraged to attend school. Some parents leave their children with albinism at home alone and hide them from the public. Learners with albinism in mainstream schools experience numerous challenges as they are exposed to ill-treatment by fellow learners who despise and ridicule them. Most teachers in mainstream schools may not have the professional competencies in handling learners with albinism.

\section{Problem}

Learners with albinism in some schools in Zambia are likely to be rejected and treated like objects of horror due to religious and cultural beliefs surrounding albinism. Studies conducted in public schools in some Sub-Saharan African countries have revealed that learners with albinism are despised, ridiculed and bullied in schools (Dart, Nkanotsang and Kowa, 2010; Benyah, 2017; Phatoli, Bila and Ross, 2015 and Ndomondo, 2015).

Studies done in South Africa and Zimbabwe by Baker, et al (2010) show that the beliefs and superstitions surrounding albinism affect their family life, socialization with others and interfere with access, retention and progression in education. The situation is similar in Malawi as reported by Braathen and Loeb (2011). The situation in Zambia could be similar to neighbouring countries as learners with albinism potentially face a lot of challenges in schools owing to their poor eyesight and sensitive skin which makes their 
learning problematic. In Zambia, the myths associated with albinism seem to have a profound influence on the lives and experiences of learners with albinism in schools. The paucity of research about educating persons with albinism in Zambia and limited exposure of teachers and teacher trainees to this condition indicate the need for a closer examination of albinism as most studies in Zambia have tended to concentrate on the visually impaired learners. It is against this backdrop that this study was set out to focus on the classroom learning experiences of learners with albinism in selected regular and special schools in Zambia.

\section{Objectives}

The following objectives were formulated for the study:

1) Establish how learners with albinism relate with their peers and teachers in regular schools.

2) Explore how learners with albinism relate with their peers and teachers in Special schools

3) Ascertain which learning environment is regarded as conducive by learners with albinism between regular and special schools.

\subsection{Research questions}

The following research questions guided the study:

1) How do learners with albinisms relate with their peers and teachers in regular schools?

2) How do learners with albinism relate with their peers and teachers in special schools?

3) Which learning environment do learners with albinism regard as conducive between regular and special schools?

\section{Material and Methods}

The study being qualitative in nature used a phenomenological approach in form of a descriptive design. Phenomenology can be defined as the exploration and description of phenomena, where phenomena refer to things, concepts or experiences as human beings experience them (Robert, 2003). In a phenomenological study, four clear set of procedures and techniques are presented. The first one being identifying the phenomenon in which the researcher is interested. Secondly, gathering descriptive accounts from respondents regarding their experience of the phenomenon. Thirdly, carefully studying the respondent's accounts with the aim of identifying any underlying commonalities and patterns and finally presenting results in the form of scholarly presentation. Whatever the particular phrasing, the common assumption is that the individual descriptive accounts, when carefully studied and considered collectively, reveal their own thematic meaning and organisation of data. Creswell (2012) posits that phenomenological design 
is a descriptive and interpretive study of how individuals experience and understand phenomenon. Methodological possibilities include the researcher participating and conducting in-depth interviews with the person or group having the experience, or carefully watching and describing the situation supporting or related to the experience (Creswell, 2012). The phenomenological study approach arose out of the desire to comprehend social phenomena in both their complexity and 'natural' context. The justification for the phenomenological approach in this study is to present an in-depth description of challenges and prospects in educating learners with albinism.

In view of the above, the researcher collected information from primary respondents who were learners with albinism themselves. And, teachers and parents of children with albinism contributed their views as secondary respondents. A total of twenty (20) respondents participated in this study. The main instrument for collecting data was the interview schedule and some two focus group discussions of learners with albinism.

\subsection{Population}

The target population comprised learners with albinism, parents of learners with albinism, teachers for learners with albinism, learners without albinism who were classmates of learners with albinism and school administrators.

\subsection{Sample and Sampling procedures}

The sample consisted of twenty participants, viz, eight learners with albinism were selected from both regular and special schools. Four school administrators, four parents of learners with albinism, three individuals with albinism who completed their secondary school education and one representative from an organization for individuals with albinism. The participants were selected from four provinces that participated in the study.

The researcher used purposive sampling procedure. This approach entails that specific participants were targeted as opposed to a random selection. Typical case sampling was used in which the sample included the most typical cases of learners with albinism, parents of learners with albinism, individuals with albinism who had completed their secondary school education and one representative from an organization for individuals with albinism. Teachers and school administrators played an important role in the identification of learners with albinism and their parents for interviews.

\subsection{Instrumentation}

Semi-structured interviews were used in order to get information from participants. According to Hall (2017), semi-structured interviews use an interview guide with some questions developed in advance and also allow the interviewer to stray from the interview guide, asking follow-up questions as the interview progresses. Interviews provide an opportunity to the researcher to carefully interact with the respondent thereby creating some level of trust between the two and maximizing on the information 
collection. This type of interview was chosen because it is easy and reliable as both persons can see each other and if the participant does not understand the question, time and space allow the interviewer to rephrase the question without much ado. The questions that were asked during the face-to-face interviews were inquisitive, exploratory and analytical questions focusing on the experiences of the participants. During the interviews, the researcher used a voice recorder with permission from participants. The recorded information was then transcribed into writing for easy interpretation of the data.

Document analysis was also used in this study, this technique is a form of qualitative research in which documents are interpreted by the researcher to give voice and meaning around an assessment topic (Cresswell, 2014). Analysing documents incorporates coding content into themes similar to how focus group or interview transcripts are analyzed (Bowen, 2009). It has been observed that document analysis is a social research method and is an important research tool in its own right and is an invaluable part of most schemes of triangulation (Bowen, 2009). In order to seek convergence and corroboration, qualitative researchers usually use at least two resources through using different data sources and methods. The purpose of triangulating is to provide a confluence of evidence that breeds credibility (Bowen, 2009). Corroborating findings across data sets can reduce the impact of potential bias by examining information collected through different methods. This study used the public document analysis in order to check on learners with albinism transcripts or records of work, this was possible for Luapula province before the COVID-19 lock down.

\subsection{Data analysis}

Analysis of data generated from interviews was informed by Interpretative Phenomenological Analysis (IPA) which considered participants' subjective interpretation of their considered perception on the challenges and opportunities of learners with albinism in regular and special schools. The narratives were thoroughly read through in order to get the general meaning and then sorted manually to identify the emerging and recurring themes which were then put together under sub-themes.

\subsection{Ethical considerations}

Ethical clearance procedures were followed and participants were informed of the voluntary nature of the study, the anonymity of their responses and the purpose of the study. Considering that the issues of individuals with albinism are sensitive in Zambia, the researcher sought ethical clearance from the University of Zambia, Humanities and Social Sciences Ethical Committee. All participants in the study were required to sign a consent form after being fully briefed on the purpose of the study. All participants were notified that participation in the study would be on voluntary basis and confidentiality and anonymity would be observed. 


\subsection{Trustworthiness}

In a bid to enhance validity and reliability of the study, a pre-test of the research instruments was conducted with one learner with albinism, one learner without albinism, one parent with child with albinism, one teacher and one school administrator. Based on recommendations from the pre-test, interview schedules were amended accordingly. In order to enhance the trustworthiness of the data, the four constructs of credibility, dependability, confirmability and transferability were taken into consideration. The researchers endeavoured to enhance credibility or plausibility of the study by providing a detailed theoretical framework, aligning the interview guides with the theoretical frame-work and by pre-testing the research tool. In order to enhance dependability or replicability of the study, the same instruments were employed by the researchers. Nonetheless, the use of a small, non-probability sample precluded transferability or generalization of the findings to the wider population of learners with albinism.

\section{Results}

The Findings based on the results obtained from the analysis in line with the research objectives and purpose are now presented. A discussion of the research findings or results follows before a conclusion and recommendations are made

\subsection{Learning experiences of learners with albinism in regular schools}

Learners with albinism were asked to share their experiences of learning in class. Most learners with Albinism gave an ominous impression about their relationship with their peers in regular schools. On the use of display formats in class such as the chalk board and other visual aids, all the learners with albinism except one hinted that they were unable to see what the teachers were writing on the board. Most learners with albinism had to go near the chalk board in order for them to see, a matter which irritated some teachers and other learners. For example, LW1 said: (Excerpt 1) "At the time I was doing my primary school, things were very difficult for me. I would try to look at the chalkboard but would not see anything, most of the teachers did not seem to understand me. So, nenze kuyenda kufupi na board." Translation: "(I would go close to the board) and read what was written there and come back to my seat and write down what I read."

Learners with albinism also indicated that when they had difficulties in reading, they became the centre of attraction among their peers. They stated that very few learners in regular schools sympathized with them, the majority of learners teased and laughed at them. This attitude made them look inferior to other learners. The majority of learners with albinism felt embarrassed by the fact that they were different from other learners in terms of reading and writing performance. Another participant LW6 who managed to do his entire education in regular school, explained that: (Excerpt 2) "I knew my sight was quite bad, but I was very intelligent. So, the teachers would ask me where I would sit so that am able to see what was written on the board. And, where I found difficulties, I would ask my friends to read for me. Now, my friends were many because I was doing very well in class." 
Asked why they left the regular schools near their homes in their districts, FGD1 said: (Excerpt 3) Kwena mulandu namenso, tulakwata amafya mukumona nangula ukulolesha. Translation: [Because of the eyes, we face challenges when it comes to seeing] FGD1 continued by saying: (Excerpt 3) Kabili ifwe bamwabi twaliba abapusana, so nangula board baibika mupepi tete iimone nagufimo. Translation: [Even if they decide to bring the board closer to me, I cannot see anything because as albino we see differently. Others can see properly while others cannot see]

Asked why they could not ask their teachers to bring the chalkboard near them so that they were able to see, FGD1 added that: (Excerpt 4) "Teachers in regular schools cannot follow what we ask them to do because they think that we do see properly just like others, but we do it deliberately. This results in a situation where I have to bring the paper closer to my eyes when reading. In doing so,I also have to bend thereby making my neck pain."

FGD2 agreed with FGD1 and said: (Excerpt 5) "The reason I left the regular school to come here... is because of sight. Unless am closer to the board I cannot see anything. Now teachers in regular schools cannot accept the idea of bringing the board near." The above sample views of some learners with albinism in regular schools demonstrate that the majority of learners with albinism had challenges reading on the chalkboard and other display formats such as visual aids because of poor vision. The majority of learners with albinism felt embarrassed by the fact that they were different from other learners in terms of reading and writing performance. Being different made them uncomfortable as they tended to lose confidence in themselves. This negative attitude was facilitated by the negative comments they received from their peers emanating from the fact that they struggled a lot with reading and writing. They further stated that during group work, some of their peers did not want them to be part of the group.

\subsection{Reading in print books}

Another area of interest in the learning experiences of learners with albinism that was mentioned was reading of books and difficulties encountered by learners with albinism. LW2 explained that: (Excerpt 6) "When it came to the reading of ink print, you know, the books are written in standard font. So, for me, I would need to bring the book very close to my face, actually, touching my face to be able to read and my friends would laugh at me."

On the same subject matter, LW3 shared the following: (Excerpt 7) "I have problems with reading in-print. Every time I read ink print, my eyes begin tearing, the tears come out as if am crying. It becomes worse when I force myself to read for more than 30 minutes." The failure to read ink-print for learners with albinism also show how much they struggle to participate in the learning process. Another participant, LW3 complained that: (Excerpt 8) "My classmates in regular school used to make funny of me. When asked to read I would bring the book closer to my face, they would laugh at me thinking I was doing it deliberately. This made me upset as I was the only one in class with such a problem. For this reason, I decided to isolate myself so as to avoid embarrassment. Even at home I decided not to play with other children." 


\subsection{Teacher treatment in regular schools}

Learners with albinism were asked to explain how teachers in regular classes treated them. A variety of responses were received on this matter. LW5 shared that: (Excerpt 9) "Teachers treated me differently. Each teacher had their own approach to me, but I remember one female teacher who refused to teach in my class because of my presence. When she entered in our class for the first time, she saw me sitting in front the front row, she stopped and looked at me in a manner that showed that she was unhappy with my presence in class. Then, she went back without saying a word... she went to the head teacher to complain that why did you give me a class where there are albinos..." LW1 explained that: (Excerpt 10) "Apart from one teacher who loved me, the rest of the teachers did not want me. I knew it because they did not want to teach my class. And, if they were forced to come there, then, they would stand very far from me. In fact, even outside class, they would not talk to me or greet me. I knew, they did not like me."

\subsection{Reasons for leaving regular schools to join special schools}

Learners with albinism were asked to explain why they left regular schools to join special schools. LW7 shared that: (Excerpt 11) "teachers at the regular school did not know how to handle me. They would find me seated in the front row, then, they would say, may be sit in the middle. And, when they are showing things to my friends, they would not get closer to me. So, I kept on wondering why..." Asked about teacher treatment in regular schools, FGD4 had this to say: (Excerpt 12) "icalenga ukuti injise kuno mulandu wakuti pano pa St. Mary's alatusakamana elyo futi balatusunga bwino sana. Nacimbi cakweba ati imibombeleyesu ifye pamo nga ama albino's yalipusanako kubanensu abashili bamwabi. Ifwe bamwabi tetitubombe mukasuba inshita itali ngefyo abanensu bengacita. Inkanda yesu tayasuminishiwa ukwikala inshita iitali mukasuba." Translation: "What made me to come here is that, teachers here at St Mary's always take good care of us. The other thing is that, we albinos are different from others, we cannot work in a sunny day for a long period of time like others because of the nature of skin." These experiences of learners with albinism encountering teachers who did not know how to handle them may be partially the reason why most of them left regular schools to join special schools. The learners with albinism complained about the manner in which they were treated by the majority of teachers in regular schools. They mentioned that teachers were not patient with them. They felt that their teachers did not give them extra attention but treated them like other learners in the classroom. They felt that teachers in regular schools did not understand that they had learning challenges and were different from other learners and therefore needed special attention. They complained that some teachers used negative comments that embarrassed them. One learner, FGD5 said: (Excerpt 13) "At my former regular school, some teachers used to get upset with me and castigate me when I failed to read and write properly. They seemed not to understand that I had challenges. They thought I was doing it deliberately to create problems for everyone in class." On the same question, another learner LW7 said: (Excerpt 14) "teachers used to humiliate me in front of other learners. They would ask me to read alone while other learners were listening, and this made me dislike school as I would pull the book to my face and the whole class would laugh at me." Responding to the same question, LW6 said: (Excerpt 15) "I was very unhappy about the 
treatment of teachers at the regular school. Some teachers made me look foolish in class. I did not receive any motivation from them, if anything they wanted me to leave the class and stop school altogether."

\subsection{Relationship between learners with albinism and peers in special schools}

Learners with albinism expressed satisfaction about their relationship with their peers in special schools. They explained that the presence of other children who were like them in the school made them feel comfortable. In a special school environment, they did not see themselves different from other learners as was the case in regular schools. Their classmates in special schools did not tease them but assisted them. One learner, FGD4 said: (Excerpt 16) "I have been at this school for almost a year and I feel at home because my classmates have accepted me the way I am. I feel accepted in the school from my classmates and teachers. My classmates do not tease me or laugh at me when am struggling to read, instead they assist me and we share desks. At the regular school nobody wanted to share a desk with me."

Responding to the same question, learner FGD2 said: (Excerpt 17) "My classmates handle me very well. They do not ridicule me as my former classmates used to trouble me at the regular school. My classmates are very friendly, and they do not fear to share things with me. Some of my classmates used to avoid me and spit whenever they came nearer me." Learner FGD3 said: (Excerpt 18) "I wouldn't have continued school at the regular school because the bullying was just too much. Some of my classmates called me bad names after school. I remember some big boys would shout at me during home time and say 'umusungu wa musonko." Translation: "a white tax collector (referring to white men who went round villages collecting tax during the colonial era)."

\subsection{Classroom friends}

The learners with albinism were asked to share how they were being treated by friends in special schools. FGD1 had this to say, (Excerpt 19) "kuno twaisa nikubanensu. Nshamonapo classmate ukunseka nangu ukuntuka. But, ngatwapusana elyo limbi bangalanda ifingi. Translation (here where we have come, we found friends. I have never seen them teasing us or insulting us. But, when we differ may be that's when someone can say a lot of things against us)." LW2 shared that: (Excerpt 20) "all my friends are blind. I guide them and we flow well in class." Almost all the responses pointed out that most of the friends who were blind or low visioned did not care about having a friend who was an albino.

\subsection{Relationship between learners with albinism and teachers in special schools}

Learners with albinism expressed satisfaction on how they were handled by teachers in special schools. All those that spoke felt that teachers in special schools understood their difficulties and were kind and patient with them. They also noted that teachers in special schools knew how to deal with their difficulties as compared to teachers in regular schools.

Learner FGD 4 said: (Excerpt 21) "teachers in special school know how to handle us. Since, I came here, I do not feel rejected by my teachers. My teachers here are friendly and kind, 
they even spend some extra time with me when I have problems in reading or writing." My academic performance has improved because of the good learning atmosphere. Commenting on the same issue, Learner FGD 6 hinted that: (Excerpt 22) "teachers in special school are not afraid of albinos. They do not keep a distance with me as compared to teachers in regular schools who never wanted to come nearer me and scolded me each time, I made a mistake or asked to sit near the chalkboard."

\subsection{Academic performance in class}

Learners with albinism were asked how their performance was in regular classes. The majority of them indicated that their performance was not good. Except for one learner with albinism who insisted that his performance was very good, the rest reported poor performance. LW7: shared the following: (Excerpt 23) "mwamene nenze nakambila kuti mu class nenze kucita kuyenda kuboard kuona vamene balemba a teacher. So, pama test nenze kubvutika kulemba. So, nenze kufeluka..... translation (as I said earlier, I would go to check on the chalkboard just to see what the teacher had written on the board. So, during tests, I used to find a lot of difficulties and that made me fail). In fact, this is one of the reasons why I stopped going to school because I am not achieving anything."

LW6 explained the following: (Excerpt 24) "In terms of performance in class, I was topping the class. In fact, even now that I have advanced, I have continued doing very well. I do not think that my albinism has an effect on my abilities in class. What I do is to ignore those who laugh at me because of my condition. But, anyway, they are very few of those who tease me." While LW1 explained that: (Excerpt 25) "I was forced to leave the regular class because my performance was not good. I mean, where you have only one teacher who is interested in your welfare, what else can you expect? So, I was trying to perform to the best of my ability in difficult circumstances. But, you know, when I went to a special school, I began topping the classes. Meaning that if I was well attended to at my primary school, I should have been doing very well."

During a Focus Group Discussion, FGD4 indicated that: (Excerpt 26): When I moved to St. Mulumba secondary school, I found that the teachers understood me. They would not make me work in the sun for a long time and in class, they talk to me and ask me to do things. In fact, I have been appointed head boy and yet I am an albino. Commenting on the same issue, LW5 shared the following: (Excerpt 27) "Pamene ninayenda kuMagwero, ninapeza kuti ma teacher yalibwino kwambiri. Sibamatinena vija vakuti, cidangwaleza. Translation: "(when I went to Magwero, I found that the teachers were very good. They do not tease us with the words albino)." All the responses from all the learners with albinism pointed out that the special education teachers were (Excerpt 28): "Ecalengele ukwebati tufumeko kulya kumasukulu uko twali tukonke ama teacher abaishiba ukwikala naifwe." Translation: "(that is why we left regular schools to follow these teachers who know how to live with us."

Responding to the same issue, LW1 said: (Excerpt 29) "I think, albinism has no impact on the academic performance of an individual. For instance, in my case, when I left my primary school in Nchelenge, I was in grade seven. At the school in Nchelenge, I was doing well. But, when I reached St. Mary's, the head teacher wanted me to start from grade four. I refused. So, I started from grade six. And, within a term, I knew how to read braille and I even started teaching 
those who were totally blind. In class, I even performed better than when I was in Nchelenge." In a focus group discussion, the learners with albinism were asked to rate their performance: FGD1 said that his performance was below average because he started school late. FGD2 said she was an average performer. FGD3 also said she was performing at an average rate. FGD4 said above average. LW4 said: (Excerpt 30) "My performance has been very good. At least, it is different from the way I used to perform at a regular school. But, my brother who is also an albino, his performance is very bad. He likes playing." From the responses of learners with albinism, it seems, albinism does not advantage the individual nor does it disadvantage the person with albinism. Their performance is like everybody else.

\subsection{Responses from head teachers on the learning experiences of learners with albinism}

Head teachers were asked to describe the learning experiences of learners with albinism in their schools. Regular schools versus special schools for learners with albinism. The head teachers were asked to explain why the learners with albinism would go to special schools rather than regular schools near their homes. HT1 explained that: (Excerpt 31) "Parents are at liberty to decide where to take their children. Some parents who bring their children to regular schools later change their minds and take their children to special schools as a way of relieving themselves the burden of caring for children with albinism. This is because most special schools have boarding facilities. The other thing is that some parents are unhappy about the attitudes of teachers and pupils towards learners with albinism, it is true that some teachers do not have the professional knowledge and skills of handling learners with albinism as such learners with albinism do not get the attention they deserve in class. Their classmates and school mates also make funny of them. As school administrators we have tried to sensitize teachers and pupils on disability issues, but not much has changed due to religious and cultural beliefs on albinism."

Commenting on the same, HT3 elaborated: (Excerpt 32) "For me, I think that in the mainstream schools, learners with albinism are not helped. You know, as special schools, we have been trained how to handle learners with disabilities. And, we teach on one to one, some individualised teaching approach. Now, in mainstream schools, they do not care about the plight of learners with albinism. It is quite common to find that instead of the learner with albinism being put in front, he or she is put anywhere in class. So, they cannot read what is written on the board. In fact, you will find that the painting of the room also contributes to the poor sight of the learner with albinism... they need bright colours and they should not face the sun." In regular schools, they will not understand if a learner with albinism puts on a cap. They will say, the child is undisciplined. But, here, as special teachers, we understand that learners with albinism put on caps to protect their eyes from the sun. In class learners with albinism may not see what is written on the board if they sit far away from the board, they should be given front sits near the board. 


\section{Discussion}

We now present the discussions of the findings based on the results which were presented. Based on the first research objective, the study revealed that the relationship between learners with albinism and their peers was negative in the regular schools. Learners with albinism were molested by other learners who despised, ridiculed and bullied them. When learners with albinism failed to read or write properly, they became objects of ridicule by their classmates who could read and write better than them. This finding is supported by Mweli and Kalenga (2009) who observed that the majority of learners who experience learning difficulties or are physically disabled have negative experiences within the school environment. Mweli and Kalenga (2009) further observed that such learners were mocked and labelled by their peers and even excluded in peergroup tasks and activities assigned in the classroom. This finding is echoed by Bhengu (2006) who found that children with disabilities were not easily accepted in regular classes. The finding on the negative relationship between learners with albinism and their classmates is further confirmed by Nugent (2008) who observed that learners with albinism were exposed to ridicule and bullying.

It was also observed that learners with albinism were not happy with the manner in which they were handled by teachers in regular schools. They complained about the demeaning treatment of teachers and how they distanced themselves from learners with albinism. They said teachers in regular classes were impatient and never gave them extra attention and that some teachers were in the habit of using negative comments that embarrassed them. This finding is supported by Mandyata \& Kamukwamba (2018) who claimed that the level of teacher awareness of special needs education was quite low in regular classes to support the learning of hearing impaired in their respective classes. Further, the study reported that teachers lack right attitudes towards differently abled learners as they interacted with them in social and academic learning environments. On the other hand, the study observed a positive relationship between learners with albinism and their classmates in special schools. This is attributed to the fact that in special schools, learners with albinism interact with learners with different disabilities such as the visually impaired, this makes them feel at home as they may have similar challenges with other learners in class. This finding is corroborated by Nugent (2008) who observed that the relationship between learners with different impairments in a special school was likely to be positive.

The results of the current study revealed a positive relationship between learners with albinism and their teachers in special school settings. Learners with albinism felt that teachers in a special school understood their difficulties and as such were patient with them. They also hinted that teachers in special schools knew how to deal with their challenges as compared to teachers in public schools. The study further revealed that learners with albinism preferred a special school environment to that of a regular school. They associated a special school environment with a home setting. This finding is supported by Lynn (2000) who argued that, in a positive school environment learners 
with disabilities would experience the feeling of success and self-value. This finding is further supported by Nugent (2008) who observed that learners in special schools seemed to be happier and had more positive experiences than those in mainstream schools.

\subsection{Learning experiences of learners with albinism in both regular and special schools} One of the questions put across to learners with albinism was for them to explain their learning experiences whether in regular schools or special education schools. There were a variety of responses on this matter. For instance, LWA1 stated that: (Excerpt 33) "I started my school at a regular one. My parents were sure that I would make it there. But, slowly, I discovered that I was not going to manage because some teachers did not want me to sit in front of the class. Though my performance was very good, some teachers hated me. Besides, my friends would laugh at me. But, I ignored some of those comments from my friends, I did not care about them. Then, one teacher saw that I began missing classes. She got interested in me and found out why I was absenting myself. She realized that my sight was also not doing well. So, she negotiated with the Kawambwa head teacher for me to move to a special school."

Similarly, in a testimony given by five boys in a focus group discussion at one of the secondary schools demonstrated that all of them had enrolled at a regular school wherever they came from. They moved to a special school because of the learning experiences which were not helpful to them. They complained that the teachers did not know how to treat them and sometimes they received death threats from the society. Coupled with the challenges in class, their parents heard about the special school for the blind and decided to take them to that school.

A study done by Mtonga and Chipili (2016) found that the majority of individuals with albinism in school were largely found in special schools and not regular schools. Similarly, Mtonga (2017) revealed that the majority of learners with visual impairments in special schools were learners with albinism. To a greater extent, it seems that learners with albinism found solace in special schools than regular schools. Mutati (2009) also notes that the majority of individuals with albinism found themselves learning in special schools and not regular institutions. Kabwe and Mandyata (2020) viewed this practice as an abnormality because individuals with albinism could learn in regular schools like any other individual as long as they were provided with the appropriate materials for their learning. The study further reports that through social interactions with peers and teachers, learners with low vision who include albinos learn to appreciate the social learning environment offered to them.

In trying to understand why learners with albinism seek to learn in special schools rather than regular schools, Mtonga and Chipili (2016) reported that learners with albinism stated that they were better protected in special schools than regular schools. While others argued that special schools did not have the requisite equipment for their learning. The learners with albinism also shared that there was a higher level of attention given to them in special schools for the blind than in regular schools. They also indicated that most of the teachers in regular schools did not have any levels of training on how to handle learners with visual impairments. Most of the learners with albinism also 
presented that they felt less stigmatised in special schools than in mainstream schools. Furthermore, Mtonga (2011), notes that the learning of children with albinism in special schools was quite problematic as learners were compelled to learn how to read braille instead of large print. The majority of the learners with albinism used their eyes to read braille. This was extremely tormenting. Knowing that the eyes of learners with albinism require special attention for them to focus on an object. Hence, making them read braille using their eyes could have certainly contributed to their poor performance. Though the learners did not like reading braille using their eyes, they had no choice because their fingers could not also be used to read braille for several reasons. For instance, due to lack of melanin, their finger sensitivity was quite poor.

Additionally, fingers cannot easily be used by someone if eyes are able to see. All these are struggles for learners with albinism in schools. Related to these findings, a study conducted by Lund and Lynch in central Malawi, (2015) reports that the majority (73\%) of visually impaired children in public schools of central Malawi had albinism, indicating that this albinism as a condition is the major cause of low vision among children in this region. These studies still confirm that it is not just in Zambia where learners with albinism are crowded in special schools. Other neighbouring countries seem to have similar situations.

From the studies presented above, it is evident that the greatest problem experienced by learners with albinism is visual impairment. Learners with albinism experience photophobia, astigmatism, nystagmus, myopia, hyperopia, amblyopia and so on. All these conditions stated here are all eye related. However, it is worth noting that despite all these visual conditions, persons with albinism are not blind. However, their sight is negatively affected because of the absence of melanin. This has seemingly created a puzzle for educationists. As a result, no specific teaching methods have been devised for learners with albinism. Many scholars feel that learners with albinism should be taught in inclusive regular classes. Yet, in practice, the learners with albinism themselves have challenges fitting in regular schools. This remains a paradox in educating learners with albinism in Zambia.

\section{Conclusion}

Learners with albinism preferred a special school environment to that of a regular school. They explained that the regular school environment was hostile to them and did not promote meaningful learning for them due to the negative attitudes of fellow pupils and teachers towards individuals with albinism. They stated that the regular school environment made them feel different from other learners, whereas the special school environment made them feel accepted in the school environment as they were able to interact with fellow learners and teachers without difficulties.

\subsection{Recommendations}

Based on the findings of the study, the study recommended the following measures: 
1) Government through the Ministry of General Education should play an important role in creating a learning environment in schools that is conducive for learners with albinism by stocking schools with the requisite learning and teaching materials.

2) Teachers in schools should be equipped with professional skills and competencies to enable them handle learners with different disabilities and in particular albinism.

3) Serving teachers in schools should be retrained by the Ministry of General Education through INSET activities such as Continuous Professional Development (CPD) on how to handle learners with albinism and other disabilities.

4) Government should take a multi-sectoral approach in raising sensitization and awareness campaigns on disability issues in the society in order to demystify the prevailing religious and cultural belief systems on disability and albinism in particular.

\section{Conflict of Interest Statement}

The authors declare no conflicts of interests.

\section{About the Authors}

Mr. Thomas Mtonga, is a Special Research Fellow in the Doctor of Philosophy in Special Education degree programme at the University of Zambia. He holds a Master of Education in Special Education of the University of Zambia and Master of Arts in Human Rights from University of Leeds in United Kingdom. Further, he has a Bachelor of Education in Special Education from university of Zambia and a Diploma in Education from Kwame Nkrumah University in Zambia. He is currently a lecturer in Special Education at the university of Zambia and is, visually impaired. He has worked as a secondary teacher of English and Religious Education in Zambian secondary schools and serves as an advisor on a number of international and national organizations dealing with persons living with disabilities. His research interests include: Advocacy and sensitization on disability and Human rights; disability, poverty and education and inclusive education methodologies.

Her Excellency, Mrs. Esther Lungu is the current First Lady of the Republic of Zambia and Founder of the Esther Lungu Foundation Trust. She is a $4^{\text {th }}$ year student in the special education degree programme at the University of Zambia and participated in the collection and processing of data as a student, that led to preparation of this article. Since assuming her tenure as First Lady in 2015, Mrs. Lungu has utilized her distinguished position to reinforce her passion for uplifting the wellbeing of humanity which work she has been doing for more than 26 years. Mrs Lungu has levered her position to focus on the economic empowerment of women living in rural and hard to reach areas. She advocates for the empowerment women and girls; maternal and child health; and for persons with disabilities. Her Excellency has joined global leaders to press for the 
elimination of child marriage, discrimination against persons with disabilities; and elimination of gender-based violence.

Dr. Kalisto Kalimaposos is Senior Lecturer and researcher in the University of Zambia, School of Education, Department of Educational Psychology, Sociology and Special Education. He holds a PhD in Sociology of Education, Master's degree in Sociology of Education and a Bachelor's degree in Sociology and Library \& Information Studies from the University of Zambia. He has published and presented papers on a wide range of educational issues in local and international journal. His research interests include equity studies in education, curriculum innovation, teacher education, sociology of disability, transformative learning, comparative and development education, primary education and entrepreneurial education.

Dr. Joseph Mandyata is a lecturer, researcher and currently Head, Department of Educational Psychology, Sociology and Special Education, School of Education, University of Zambia. He has researched, presented papers and published several articles in the field of special and inclusive education; guidance and counselling in local and international journals. He holds a PhD in Special Education, Master of Education in Special Education and a Bachelor of Arts with Education Degree from the University of Zambia. He lectures in special education; inclusive education and guidance and counselling at both postgraduate and undergraduate levels. His research interests are in: Policies and Management of Special and Inclusive education; Partnerships in Inclusive Education; Guidance and Counselling, Disability, Education and Poverty. Some of his works appear under Research gate and University of Zambia website - institutional repository as well as academia platforms.

\section{References}

Baker, C., Lund, P., Nyathi, R. And Taylor, J. (2010). The Myths Surrounding People with Albinism in South Africa and Zimbabwe. Journal of African Cultural Studies, Vol. 22, No. 2 Pp. 169-181 http://www.jstor.org/stable/41428130, Accessed: 24-01-2018 $14: 52$.

Bandui, M. (2016). Albinism-Symptoms, Causes, Treatment, Facts, Pictures. http://byebyedoctor.com/albinism/.

Benyah, F. (2017). Equally able, differently looking: Discrimination and physical violence against persons with albinism in Ghana. Journal for the study of religion. 30,1 pp. 161-188.

Bhengu, M. J. (2006). Ubuntu: The global philosophy for mankind. Cape Town: Lotsha Publications.

Braathen, S. H. \& Ingstad, B. (2006). Albinism in Malawi: Knowledge and Beliefs from an African Setting. Disability $\mathcal{E}$ Society, 21 (6), 599-611. Doi: 10.1080/09687590600918081. 
Bradleyj, K. (2014). Albinism and Its Implications with Vision. Journal of The American Society of Ophthalmic Registered Nurses. Pp.12-23.

Creswell, J. W. (2008). Educational research: Planning, conducting and evaluating quantitative and qualitative research. Upper Saddle, NJ. Prentice Hall.

Creswell, J. W. (2014). Research design: qualitative quantitative and mixed methods approaches. Thousand Oaks, CA. SAGE.

Dart, G. Nkanotsang, T., Chizwe, O. and Kowa, L. (2010). Albinism in Botswana junior secondary schools - a double case study. British Journal of Special Education. Volume 37. Number 2. Pp. 77-86.

Gaigher, R. J., Lund, P. M. Makuya, E. (2002). A Sociological Study of Children with Albinism at A Special School in The Limpopo Province. Curationis 25: 4-11. /63 (Jan. 18, 2016).

Hall, S. (2017). The difference between structure and semi-structured interviews in qualitative research. Viewed $20^{\text {th }}$ May, 2020 from https://bizfluent.com/info12050751-difference-between-structured-semi-structured.

Kabwe, A. \& Mandyata, J. (2020). Social experiences of Pupils with Low Vision in Selected Regular Secondary Schools of Lusaka and Mbala District, Zambia. European Journal of Special Education Research, 5(4), 128-146

Lund, P. M., \& Lynch, P. (2012). Promoting the Educational Inclusion of Children with Albinism in Sub-Saharan Africa: Evidence from Malawi. Commonwealth Education Partnerships, 13 ,

http://www.sightsavers.net/in depth/research/publications and reports/

Lund, P. M. \& Gaigher, R. (2002). A health intervention programme for students with albinism, University of Venda, South Africa, viewed 10 September 2020, from http://www.saassap.co.za/dl/userfile/documents.

Lund, P. (2000). Educating Children with Albinism in South Africa. Progress in Education 9: 99-113.

Lund, P. (2001). Health and Education of Children with Albinism in Zimbabwe. Health Education Research: Theory and Practice16, No. 1: 1-7.

Lund, P. M. and Gaigher, R. (2002). A Health Intervention Programme for Children with Albinism at a Special School in South Africa. Health Education Research, 17, 365-372.

Lynn, H. P. (2000). A dyslexic child in the classroom. Dyslexia Davis Association International, viewed $24^{\text {th }}$ September 2020, from www.dyslexia.com

Mandyata, J. \& Kamukwamba, K. L. (2018). Stakeholders' Views on Use of Sign Language Alone as a Medium of Instruction for Hearing Impaired in Zambian Primary Schools. International Journal of Special Education. 33(1), 62-76.

Mtonga, T. (2015). A Critical Evaluation of the Implementation of Article 24 of the CRPD in Zambia: A Mockery of Human Rights. Leeds: University of Leeds (Unpublished LLM International Human Rights Law Dissertation).

Mtonga, T. Chipili, T. C. (2016). Access to Education by Learners with Albinism in Zambia: A Case of Selected Schools. Pretoria: Disability Rights Conference Proceedings. 
Mweli, P. and Kalenga, C. R. (2009). Exploring learners' experiences of inclusive education: the voice of the voiceless. https://www.researchgate.net/publication/263534912 Exploring Learners' Exper iences of Inclusive Education The Voice of the Voiceless.

Ndomondo, E. (2015). Educating children with albinism in Tanzanian regular secondary schools: Challenges and opportunities. International Journal of Education and Research. Vol. 3. No.6 June. Pp. 389-400.

Nasr, S. L. (2010). How albinism works, viewed 07 March 2020, from http://www.Health.Howstuffworks.com/skincare/problems/medical/albinism.htm/printable.

Ntinda, R. N. (2008). Customary practices and children with albinism in Namibia: A constitutional challenge? Children's rights in Namibia. http://en.afrk.com/article13487.html. Viewed 20 October 2020.

Phatoli, R., Bila, N. \& Ross, E. (2015). Being black in a white skin: Beliefs and stereotypes around albinism at a South African University, African Journal of Disability 4 (1), pp. Art. \#106, 10pages. http://dx.doi.org/10.4102/AJOD.V4I1.106.

Stine, S. B. \& Ingstad, B. (2006). Albinism in Malawi Knowledge and Beliefs from an African Setting, Disability \& Society. Journal of Disability 21:6, 599.

Taylor, J., \& Lund, P. M. (2008). Experiences of A feasibility study of children with Albinism in Zimbabwe: A Discussion Paper. International Journal of Nursing Studies 45, No. 8: 1247-56.

Thompson, L. S. (2013). Dyslexia: An investigation of teacher awareness in mainstream high schools in the Western Cape, University of South Africa, Pretoria. 
Thomas Mtonga, Esther Lungu, Kalisto Kalimaposo, Joseph Mandyata

EXCLUSION IN INCLUSION: EXPERIENCES OF LEARNERS WITH ALBINISM

IN SELECTED MAINSTREAM AND SPECIAL SCHOOLS IN ZAMBIA

Creative Commons licensing terms

Authors will retain the copyright of their published articles agreeing that a Creative Commons Attribution 4.0 International License (CC BY 4.0) terms will be applied to their work. Under the terms of this license, no permission is required from the author(s) or publisher for members of the community to copy, distribute, transmit or adapt the article content, providing a proper, prominent and unambiguous attribution to the authors in a manner that makes clear that the materials are being reused under permission of a Creative Commons License. Views, opinions and conclusions expressed in this research article are views, opinions and conclusions of the author(s). Open Access Publishing Group and European Journal of Special Education Research shall not be responsible or answerable for any loss, damage or liability caused in relation to/arising out of conflict of interests, copyright violations and inappropriate or inaccurate use of any kind content related or integrated on the research work. All the published works are meeting the Open Access Publishing requirements and can be freely accessed, shared, modified, distributed and used in educational, commercial and non-commercial purposes under a Creative Commons Attribution 4.0 International License (CC BY 4.0). 